\title{
Prevalence and risk factors for inter-generational Sex: a cross-sectional cluster survey of Barbadian females aged 15-19
}

Nicole Drakes ${ }^{1}$, Clarissa Perks ${ }^{2}$, Alok Kumar ${ }^{3}$, Kim Quimby ${ }^{4}$, Colin Clarke 5 , Rajul Patel ${ }^{2}$, lan R Hambleton ${ }^{4}$ and R Clive Landis ${ }^{4,6^{*}}$

\begin{abstract}
Background: The aim of this study was to establish the prevalence and risk factors for intergenerational (IG)-sex in females aged 15-19 residing in Barbados.

Methods: This cross sectional cluster survey was conducted in a $2.6 \%$ national sample in the age range $(n=261)$ recruited from multiple polling districts chosen with a probability proportional to size. Consent was obtained from participants aged $\geq 18$ years or from parents/guardians of participants $<18$ years, with participant assent. The prevalence of age at first sex was analyzed using a life table approach and risk factors for IG sex (defined as sexual relations with a male 10 or more years older) were analyzed by logistic regression, adjusting for age.

Results: $51.0 \%$ of adolescent females in the survey reported ever having had sex, among whom prevalence of IG-sex was 13.2\% (95\% Cl: 6.7-19.8) at first sex, 29.0\% (22.3-35.7) within the preceding twelve months, and 34.8\% (24.3-45.4) ever. Condom use at first sex was positively related to willingness to have sex ( $F$ statistic $=9.8, p=0.001$ ). The strongest determinant for IG-sex was age of sexual debut (age adjusted Odds Ratio [95\% Cl]: 0.58[0.41-0.83]), followed by money or gifts received from the partner (2.91[1.17-7.23] and self-esteem (0.33[0.11-0.95]).

Conclusions: The survey establishes a high rate of IG-sex in Barbados, a 'high income' country. Most insightful is that risk of IG-sex nearly halved for every year at which first sex was delayed. A high proportion of coerced sex was reported at first sexual experience and this was linked to poor condom use. Affirmative prevention approaches are recommended to boost self-acclamation of adolescent women within less coercive relationships, especially during their first sexual encounter.
\end{abstract}

\section{Background}

The Caribbean region has the second highest prevalence of HIV worldwide, behind sub-Saharan Africa, and is one of two regions (the other being Africa) where the proportion of young women living with HIV in the 15-24 age group outnumbers males [1,2]. In Barbados the overall prevalence of HIV remains higher in men, but in the age group 10-19 it is more prevalent in women [2]. This signifies a major shift for a disease originally concentrated within the male population. Multiple, intergenerational

\footnotetext{
* Correspondence: clive.landis@cavehill.uwi.edu

${ }^{4}$ Chronic Disease Research Centre, The University of the West Indies, Bridgetown, Barbados

${ }^{6}$ Edmund Cohen Laboratory for Vascular Research, Chronic Disease Research Centre, University of the West Indies, Bridgetown BB11115, Barbados Full list of author information is available at the end of the article
}

and transactional sexual partnering, along with cultural norms and gender roles that limit women's sexual health choices, are implicated as driving this epidemiologic transition to young women [3-5].

Inter-generational (IG)-sex is generally defined in the literature as heterosexual intercourse with a non-marital partner ten or more years older [6-8]. Also referred to as cross generational sex or the 'sugar daddy' syndrome, it is primarily characterised by relationships between younger women and older men $[9,10]$. Research in Africa supports the existence of a link between IG-sex and HIV infection among adolescent females. In sub-Saharan Africa, adolescent women aged 15-24 were between 2 to 4 times more likely to be infected than their male contemporaries [11], while research by Kelly et al. (2003) identified large age differences in sexual relationships as a contributing factor

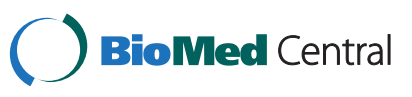


to HIV prevalence [12]. A study of adolescent women aged 15-24 in rural Zimbabwe concluded that each one-year increase in age difference between partners was associated with a 4 percent increase in risk of HIV infection [13].

Transactional sex, often defined as sex in exchange for financial or material gain, can place women's health at risk $[7,12-15]$. These relationships, commonly intergenerational, are linked with reduced condom use $[4,6]$. The greater the asymmetry in partner age and wealth, the less room for sexual negotiation on the female's part [9,16-19]. Despite high levels of HIV awareness and education in the Caribbean, levels of reported condom use remain inconsistent [5,20-23]. As in other parts of the world, the ability to exercise condom use by young females is impacted by entrenched gender stereotypes, cultural attitudes towards sex, asymmetric power distribution within relationships, sexual violence, and unequal access to resources [4,17,24-27].

Information on IG-sex is quite sparse for the Caribbean. However, Demographic Health Surveys and KABP studies have estimated IG-sex prevalence among sexually active females aged 15-19 years within the preceding 12 months ranging from 3.7\% in St. Kitts \& Nevis, 6\% in The Dominican Republic, 7.6\% in Dominica, 9.8\% in Haiti, $17.4 \%$ in Antigua \& Barbuda, and $17.7 \%$ in Grenada $[20,28]$. Two focus group studies conducted in Jamaica indicated that girls having relationships with older men were regarded as 'common' and 'normal' among peers, though not necessarily by the family $[29,30]$. A series of Demographic Health Surveys in African countries revealed a range of IG-sex prevalence in 15-19 year olds from 3.3\% in Malawi, $9.6 \%$ in Ghana, $13.7 \%$ in Tanzania, $19.3 \%$ in Uganda, and $25.5 \%$ in Nigeria [31-35]. The transactional element that often characterizes these types of relationship is a strong motivating factor, not only through accruing material or social benefits but also by affirmation of selfworth [7,36-38]. Indeed, the meaning of transactional sex within a given cultural context remains the subject of debate $[38,39]$.

Our survey therefore sought to measure prevalence of IG-sex as a primary outcome measure in a nationally representative survey, conducted in adolescent females aged 15-19 residing in Barbados. Determinants examined for IG-sex included transactional sex, age, age at first sex, religious worship, and psycho-social measures of selfesteem, sense of personal power, and peer pressure. The findings were contrasted with the determinants for sex with any age partner in the same survey population.

\section{Methods}

\section{Study population}

The study was completed among adolescent females aged 15 to 19 years, who were sampled from multiple polling districts (chosen with a probability proportional to size) to achieve a target $3.0 \%$ sample of the population of 15-19 year old women in Barbados (there were 10,045 women in this age range according to the adjusted 2000 census). The survey returned 261 completed questionnaires, an $87 \%$ response rate that yielded a final $2.6 \%$ sample of the population in the age group. The sample design was a two-stage random sample of girls aged between 15 and 19. Stage 1 consisted of selecting polling districts with probability proportional to size. The island is divided into 313 polling districts and a 5\% sample of districts yielded 16 districts. The second stage of sampling was done by interviewers within each polling district, who selected every fifth household for inclusion after a randomly chosen start. All eligible girls within each household were selected for inclusion in the survey.

\section{Informed consent}

All surveys were conducted with informed consent and IRB approval, in accordance with the principles of the Declaration of Helsinki as revised in 2000. The survey was interviewer-administered with Youth Commissioners of the Youth Department selected on the basis of experience in fieldwork and working with young people. A number of provisions were taken to maintain confidentiality in this sensitive youth survey: interviewers were assigned to a polling district outside of the area in which they generally worked; deliberate non-recording of personal identifiers such as names and addresses ensured anonymity of respondents and confidentiality of the data collected; written informed consent was obtained from participants aged 18 years or older, or from parents/guardians of participants aged 17 years or younger, with the assent of the participant; parents or guardians were not permitted to sit-in on interviews. Interviewers were trained to answer any queries posed by the respondents or their parents/guardians. Ethical approval for the study protocol was obtained from the ethics committee serving the Barbados Ministry of Health and The University of the West Indies, as well as the IRB of the University of Southampton, UK.

\section{Survey instrument}

The survey instrument was designed by The University of the West Indies (UWI) and The National HIV/AIDS Commission (NHAC) based on the Interpersonal Violence (IPV) survey and previous KABP surveys conducted in Barbados, Jamaica and several African states [22,23,26]. The questionnaire consisted of 98 items, all closed-ended questions, seeking to capture socio-demographic data on the target group as well as information on the respondent's sexual history, economic indicators, the practice of transactional sex, relationship dynamics (same-age vs intergenerational partners), and possible determinants of sex (sense of self-esteem, personal power, peer pressure, 
perceived financial status, and religious worship attendance). Validated instruments included scales for peer pressure, personal power, and self-esteem [40-43]. "Pregnancy/ STD Prevention" of the Sexual Assertiveness Scale (Morokoff) was included, but not subscales on "Initiation" and "Refusal" that were considered too sensitive for this youth survey [44]. The experience at first sex, including condom use, willingness to have sex, and partner's age, was assessed using questions asked in successive KABP surveys in Barbados [22]. Religious worship was assessed with the question: "do you attend religious service?", scored on a scale "never, a few times a year, monthly, weekly, more than weekly". Perceived financial distress in this youth population was assessed by the following subjective statements: "I have enough money to cover my daily necessities" and "I have enough money to cover luxuries", scored on a scale "strongly agree, agree, disagree, strongly disagree". A pre-test of the survey instrument was conducted on a similar population to the respondent population with the aim of identifying any weaknesses in questionnaire design and providing practice for fieldworkers. Double data entry was performed to minimize transcription error.

\section{Key outcome measures}

The primary outcome measure was inter-generational sex. The UNAIDS definition of inter-generational relationships (also referred to as cross-generational) was used to guide the survey [8]. IG Sex was therefore defined as heterosexual intercourse with an unmarried male partner 10 or more years older. IG prevalence was measured using 3 items: respondent self-reports of sexual intercourse with a male partner 10 or more years older at the first sexual encounter; sexual intercourse within the past 12 months with a male partner 10 or more years older; and ever having had sexual intercourse with a male partner 10 or more years older. Transactional sex is the exchange of money, food and other items for sex $[10,14,15,38]$. The survey asked respondents if they had ever exchanged sex in exchange for money or gifts, and the question was repeated for sameage and older partners. Several predictors of IG sex were incorporated into the survey, some of which were based on individual items: age at first sexual encounter; age of first sexual partner; religious service attendance; and psychosocial variables of self-esteem, sense of personal power and peer pressure.

\section{Statistical methods}

The prevalence rates for inter-generational sex (yes/no) were calculated with associated 95\% confidence intervals for the following scenarios: at first sex, in the past 12months, and ever. In secondary analyses, associations between selected sexual and psychosocial characteristics and the probability of reporting having had sex or intergenerational sex were examined used a series of logistic regression analyses, reporting odds ratios (unadjusted and age-adjusted) and their associated 95\% confidence intervals. For all prevalence calculations and regression analyses, standard errors and 95\% confidence intervals reflect the two-stage survey design and the increased correlation of participants recruited from a single household. Such survey designs inflate the standard errors of any point estimates, and a Taylor linearization was used for all variance estimation. The change in the proportion of respondents reporting sexual activity with age was quantified using a univariate logistic regression, and reported using an odds ratio and associated $95 \%$ confidence interval. To calculate the age at first sex a life table approach was used, which calculated the cumulative proportion having sex at each year of age up to 19 . The technique allowed for those adolescents who had never had sex to be censored at their current age. Although all analyses relied on 95\% confidence intervals to describe the strength of associations between possible predictors and model outcomes, for completeness p-values were occasionally calculated for primary associations of interest, and in these situations exact $\mathrm{p}$-values were presented to clarify the strength of the statistical relationships. All analyses were performed using Stata statistical software (version 13, StataCorp LP, College Station, Texas, USA).

\section{Results}

\section{Characteristics of survey population stratified by sexual history}

The survey returned 261 completed questionnaires, representing an $87 \%$ response rate and an overall $2.6 \%$ sample of the female population within the 15-19 year age range in Barbados. The average item non-response rate was minimal (5.3\%). The sexual history of 259 females who responded to this item is shown in Table 1. Respondents were stratified according to age and type of sex engaged in (i.e. never had sex, had sex but not IG-sex, had IG-sex). 127 respondents reported never having had sex, 86 respondents reported having had sex but not IGsex, while 46 respondents reported having had IG-sex. The proportion of adolescents who reported having had sex was strongly age-related, with prevalence of any sex (oral, vaginal, anal) rising from $30 \%$ among 15 year-olds to $84 \%$ among 19 year-olds (data not shown; $\mathrm{F}$ statistic $=$ 7.4, $\mathrm{p}<0.001$ ). Table 1 also categorizes responses to questions on perceived financial distress and religious worship attendance, stratified according to sexual history. This group of adolescent females reported perceived financial distress, with almost $40 \%$ of the total survey population disagreeing or strongly disagreeing that they had sufficient money to cover daily necessities, while over two thirds felt 
Table 1 Selected characteristics of 259 Barbadian females aged 15 to 19, stratified by sexual history (never had sex, had sex but not inter-generational sex, had inter-generational sex)

\begin{tabular}{|c|c|c|c|c|}
\hline & $\begin{array}{l}\text { Never had sex } \\
\mathrm{N}=127 \\
\end{array}$ & $\begin{array}{l}\text { Had sex but not inter-generational sex } \\
\qquad \mathrm{N}=86\end{array}$ & $\begin{array}{l}\text { Had inter-generational sex } \\
\qquad \mathrm{N}=46\end{array}$ & $\begin{array}{c}\text { Total } \\
\mathrm{N}=\mathbf{2 5 6}\end{array}$ \\
\hline Characteristic & $\mathrm{n}$ (percent) & n (percent) & $\mathrm{n}$ (percent) & $\mathrm{n}$ (percent) \\
\hline \multicolumn{5}{|l|}{ Age $(n=256)$} \\
\hline 15 & $39(30.7)$ & $9(10.8)$ & $8(17.4)$ & $56(21.9)$ \\
\hline 16 & $38(29.9)$ & $9(10.8)$ & $3(6.5)$ & $50(19.5)$ \\
\hline 17 & $23(18.1)$ & $27(32.5)$ & $5(10.9)$ & $55(21.5)$ \\
\hline 18 & $20(15.8)$ & $18(21.7)$ & $12(26.1)$ & $50(19.5)$ \\
\hline 19 & $7(5.5)$ & $20(24.1)$ & $18(39.1)$ & $45(17.6)$ \\
\hline \multicolumn{5}{|c|}{ Enough money to cover necessities $(n=251)$} \\
\hline Strongly agree & $12(9.8)$ & $6(7.3)$ & $0(-)$ & $18(7.2)$ \\
\hline Agree & $60(48.8)$ & $47(57.3)$ & $27(58.7)$ & $134(53.4)$ \\
\hline Disagree & $39(31.7)$ & $23(28.1)$ & $17(37.0)$ & 79 (31.5) \\
\hline Strongly disagree & $12(9.8)$ & $6(7.3)$ & $2(4.3)$ & $20(8.0)$ \\
\hline \multicolumn{5}{|c|}{ Enough money to cover luxuries $(n=245)$} \\
\hline Strongly agree & $7(5.8)$ & $1(1.2)$ & $1(2.3)$ & $9(3.7)$ \\
\hline Agree & $35(29.2)$ & $22(27.2)$ & $13(29.6)$ & $70(28.6)$ \\
\hline Disagree & $61(50.8)$ & $48(59.3)$ & $27(61.4)$ & $136(55.5)$ \\
\hline Strongly disagree & $17(14.2)$ & $10(12.4)$ & $3(6.8)$ & $30(12.2)$ \\
\hline \multicolumn{5}{|c|}{ Do you attend religious services $(n=240)$} \\
\hline Never & $31(25.8)$ & $39(47.6)$ & $22(57.9)$ & $92(38.3)$ \\
\hline Less than monthly & $6(5.0)$ & $12(14.6)$ & $6(15.8)$ & $24(10.0)$ \\
\hline Monthly & $11(9.2)$ & $11(13.4)$ & $3(7.9)$ & $25(10.4)$ \\
\hline Weekly & $41(34.2)$ & $14(17.1)$ & $4(10.5)$ & $59(24.6)$ \\
\hline More than weekly & $31(25.8)$ & $6(7.3)$ & $5(7.9)$ & $40(16.7)$ \\
\hline
\end{tabular}

they did not have enough money to cover luxuries. Religious worship attendance revealed $40.9 \%$ of respondents attended service regularly (weekly or $>$ weekly), 20.6\% attended service occasionally, and 38.4\% never attended a religious service. Respondents were Christian (54.9\%), nonChristian (6.2\%), and of no religious affiliation (38.9\%).

\section{Age at first sex}

The age at first sex is illustrated in Figure 1. In this group of adolescent females aged 15 to 19 at the time of interview, $7.3 \%$ reported their age at first sex before 13 years of age, $11.3 \%$ before 14 years, $21.5 \%$ before 15 years, $31.8 \%$ before 16 years, $46.9 \%$ before 17 years, $62.6 \%$ before 18 years, and $66.5 \%$ before 19 years. Using this censored life table analysis, $25 \%$ of participants had had sex by 15 years of age (lower quartile), and $50 \%$ had had sex by 17 years of age (median).

\section{Sexual history and inter-generational sex}

The key outcome measure of this survey was the prevalence of IG-sex, reported in Table 2. Overall, 51.0\% (95\% CI: $42.5-59.4, \mathrm{n}=134$ ) of respondents reported ever having had sex and 17.8\% (11.3 - 24.3, $\mathrm{n}=46)$ reported a sexual history with a partner 10 or more years older. As a proportion of females who had ever had sex, IGsex was reported at the first sexual encounter by $13.2 \%$ (95\% CI: $6.7-19.8, \mathrm{n}=16$ ), 29.0\% (95\% CI: $22.3-35.7$, $\mathrm{n}=31$ ) within the preceding twelve months, and $34.8 \%$ (95\% CI: $24.3-45.4, \mathrm{n}=46)$ ever. The age difference of the male partner at the first sexual encounter was examined in further detail: the age difference was reported to be 10 or more years older in 13.2\% (95\% CI: 6.7 - 19.8, $\mathrm{n}=16$ ) of respondents, $5-9$ years older in $25.6 \%$ of respondents (95\% CI: 15.6 - 35.7, $\mathrm{n}=31$ ), "older, unsure how much" in $14.9 \%$ (95\% CI: $7.0-22.8, \mathrm{n}=18$ ), and of similar age in $46.3 \%$ of respondents (95\% CI: $37.8-54.7$, $\mathrm{n}=56$ ). Zero percent of girls in the survey reported a younger partner at first sex. Money or gifts were equally likely to be received from a same-age versus an IG partner. Condoms were used by 68/125 of girls during their first sexual encounter (54.4\%, CI: $40.4 \%$ to $68.4 \%$ ). Condom use was strongly related to willingness to have sex. A sizeable proportion of girls were either "persuaded to have sex" (30.8\%, CI: $21.2 \%$ to $40.3 \%, \mathrm{n}=40$ ) or "did not 


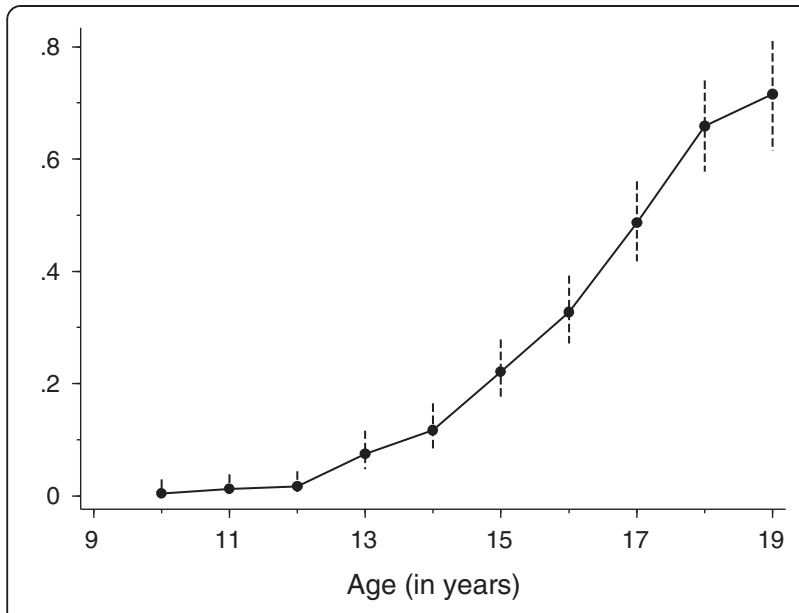

Figure 1 Age at first sex among 261 Barbadian females aged 15-19. The distribution of age at first sex was generated from censored observations by survival analysis. The input data were age of the respondent, whether or not they ever had sex and if applicable recalled age at first sex. In calculating a survival function describing the probability of remaining a virgin, reported age at first sex is the 'death' event and those who never had intercourse are censored at their current age.

want to have sex" and (6.9\%, CI: $2.9 \%$ to $11.0 \%, \mathrm{n}=9$ ). Condom use was $68 \%$ among those who "wanted to have sex" $(\mathrm{n}=81), 37 \%$ among those who were "persuaded to have sex", and a condom was never used among those who "did not want to have sex" (F statistic $=9.8, \mathrm{p}=$ 0.001). Multiple partnering in sexually active females showed that $30.2 \%$ of respondents reported more than one partner in the past 12 months: $18.9 \%$ reported 2 partners, $5.0 \% 3$ partners, $3.3 \% 4$ partners, $3.0 \% 5$ or more partners.

\section{Determinants for the likelihood of having had sex (any-age partner)}

A range of demographic, economic, and psycho-social factors were examined for their relationship with the likelihood of having had sex (any-age partner) in this adolescent female population. As expected, age was a strong predictor of having had sex, with the odds increasing by 1.87 (95\% CI 1.43 - 2.45) for every additional year of age. All other factors were therefore preadjusted for age and are presented on the right of Table 3. We could not demonstrate a link between financial security and the likelihood of having had sex, despite the evidence for perceived financial distress captured in Table 1. Religious service attendance was strongly related to having had sex, with those adolescent females not attending church reporting an almost three times greater chance of having had sex (odds ratio 2.86, $95 \%$ CI 1.85 - 4.41). More specifically, those either not attending church or attending church monthly or less were more likely to report having had sex compared to those attending church weekly or more than weekly $(\mathrm{p}=$ 0.01 or stronger in all cases). Finally, a constellation of psycho-social factors, including self-esteem, sense of personal power, and peer-pressure, were examined for their association with having had sex in this adolescent female population. Whereas increasing peer pressure significantly increased the chance of reporting sexual activity (age adjusted Odds Ratio [95\% CI]: 4.4 [2.34-8.29], higher levels of self-esteem $(0.10$ [0.03-0.37]) and 'sense of personal power' $(0.42[0.20-0.85])$ statistically significantly decreased the chance. Given the statistically significant effects of peer pressure and religious service attendance on the probability of having had sex, the relationship between peer pressure and religious service attendance was examined as a post-hoc analysis. A regression output demonstrated that the peer pressure index (and so peer pressure) increased among those who did not attend a religious service, relative to those who did (coefficient $=0.26$, 95\% CI 0.13 to 0.39). Furthermore, the frequency of religious service attendance was associated with a systematic downward trend in peer pressure $(\mathrm{p}=0.01)$.

\section{Determinants for inter-generational sex}

Unadjusted and age-adjusted odds of reporting IG-sex are shown in Table 4. The unadjusted odds ratio of reporting IG-sex rose by 1.56 for every additional year of age (95\% CI $0.91-2.68)$, as expected. More insightful was that the chance of IG-sex decreased as age at first sex increased (age-adjusted odds ratio $0.58,95 \%$ CI $0.41-0.83$ ). This amounts to almost a halving of risk for every additional year of age at which the first sexual encounter occurred. There was no association of IG-sex with a perception towards insufficient money to cover necessities $(\mathrm{p}=0.97)$ but there was a mild trend towards perceived financial insufficiency as it related to purchase of luxuries $(p=0.27)$. Money or gifts from the partner was statistically significantly associated with IG-sex $(\mathrm{OR}=2.91,95 \% \mathrm{CI}$ $1.17-7.23)$. Religious service attendance was not associated with the odds of reporting IG-sex $(\mathrm{p}=0.82)$. Of the psychosocial factors, we could not demonstrate a link between peer-pressure or sense of personal power with IGsex. However, self-esteem was statistically significantly associated with IG-sex: i.e. higher self-esteem was associated with a three-fold reduction in IG-sex (OR $=0.33$, 95\% CI $0.11-0.95)$. Having more than one partner in the past 12 months was associated with IG-sex (age adjusted odds ratio 3.27 , $95 \%$ CI 1.55 to 6.91 , not shown).

\section{Discussion}

The present study is the first to report prevalence rates of IG-sex among adolescent females in Barbados in a nationally representative survey. The rate of IG-sex among sexually active females aged $15-19$ is $29.0 \%$ (95\% CI: 
Table 2 Sexual history among 261 Barbadian females aged 15 to 19, and selected sexual characteristics among 134 Barbadian females who have had sex at least once

\begin{tabular}{|c|c|c|c|c|}
\hline Characteristics & Response & Number & $\%$ & $95 \% \mathrm{Cl}$ \\
\hline \multicolumn{5}{|c|}{ Sexual history: prevalence of sexual activity $\dagger$} \\
\hline Ever had sex? & $259 / 261$ & 132 & 51.0 & 42.5 to 59.4 \\
\hline Ever had oral sex? & $243 / 261$ & 67 & 27.6 & 18.7 to 36.4 \\
\hline Ever had vaginal sex? & $258 / 261$ & 126 & 48.8 & 40.9 to 56.8 \\
\hline Ever had anal sex? & $237 / 261$ & 15 & 6.3 & 2.7 to 9.9 \\
\hline \multicolumn{5}{|c|}{ Sexual history: prevalence of Inter-Generational sex } \\
\hline At first sex & $248 / 261$ & 16 & 6.5 & 3.1 to 9.8 \\
\hline Within past 12 months & $234 / 261$ & 31 & 13.2 & 8.3 to 18.2 \\
\hline At any time & $259 / 261$ & 46 & 17.8 & 11.3 to 24.3 \\
\hline \multicolumn{5}{|c|}{ Characteristics among females who have had sex at least once } \\
\hline Inter-Generational sex at first sex & $121 / 132$ & 16 & 13.2 & 6.7 to 19.8 \\
\hline Inter-Generational sex in past 12 months & $107 / 132$ & 31 & 29.0 & 22.3 to 35.7 \\
\hline Inter-Generational sex ever? & $132 / 132$ & 46 & 34.8 & 24.3 to 45.4 \\
\hline Age of partner at first sex & $121 / 132$ & & & \\
\hline 10 or more years older & & 16 & 13.2 & 6.7 to 19.8 \\
\hline 5 to 9 years older & & 31 & 25.6 & 15.6 to 35.7 \\
\hline Older, unsure how much & & 18 & 14.9 & 7.0 to 22.8 \\
\hline About the same age & & 56 & 46.3 & 37.8 to 54.7 \\
\hline Money or gifts from sexual partner? & $125 / 132$ & 69 & 55.2 & 43.5 to 66.9 \\
\hline Money or gifts from same-age partner? & $61 / 69$ & 22 & 36.1 & 24.2 to 49.4 \\
\hline Money or gifts from older partner? & $61 / 69$ & 20 & 32.8 & 21.3 to 46.0 \\
\hline Condom used at first sexual encounter? & $125 / 132$ & 68 & 54.4 & 40.4 to 68.4 \\
\hline Willingness at first sex? & $130 / 132$ & & & \\
\hline wanted to have sex & & 81 & 62.3 & 52.6 to 72.0 \\
\hline persuaded to have sex & & 40 & 30.8 & 21.2 to 40.3 \\
\hline did not want to have sex & & 9 & 6.9 & 2.9 to 11.0 \\
\hline Sex in past 12 months? & $129 / 132$ & 105 & 81.4 & 70.7 to 92.1 \\
\hline Number of partners in past 12 months? & $132 / 132$ & & & \\
\hline 0 & & 33 & 25.0 & 13.7 to 36.3 \\
\hline 1 & & 59 & 44.7 & 34.8 to 54.5 \\
\hline 2 & & 25 & 18.9 & 10.8 to 27.1 \\
\hline $3-4$ & & 11 & 8.3 & 2.7 to 14.0 \\
\hline $5+$ & & 4 & 3.0 & 0.3 to 5.7 \\
\hline
\end{tabular}

† Ever had sex $(\mathrm{N}=259$ respondents). Compared to Table $1(\mathrm{~N}=256)$. This was due to three participants without known age.

22.3 - 35.7), higher than the only existing survey data from the Eastern Caribbean and comparable to rates at the uppermost range in Africa [20,28,31-35]. The proportion of females who reported IG-sex at their first sexual experience, 13.2\% (95\% CI: 6.7 - 19.8), was consistent with a KABP survey conducted in Barbados in 2011 that reported $11.4 \%$ (unpublished). The relatively high rates of IG-sex reported here are therefore consistent with the claim made in the UNAIDS Caribbean Report of 2008 that it is 'common practise' among adolescent girls in the Caribbean to maintain relationships with older men [3].

The high rates of IG-sex were not expected based purely on an assumed link with poverty or lack of education among adolescent girls. In rural Africa, it has been established that poverty, in the context of poor access to education, healthcare, and employment opportunities, urges women into such relationships $[7,17,45,46]$. Barbados is classified as a 'high income' country by the World Bank with a gini coefficient (a measure of income 
Table 3 Unadjusted and age-adjusted associations for ever having had sex (yes/no)

\begin{tabular}{llcc}
\hline Factor & $\mathbf{N}$ & Unadjusted odds ratio (95\% Cl) & Age adjusted odds ratio (95\% Cl) $\dagger$ \\
\hline Age & 256 & $1.87(1.43-2.45)$ & - \\
Enough money to cover necessities & 250 & $0.98(0.64-1.49)$ & $1.01(0.64-1.60)$ \\
Enough money to cover luxuries & 244 & $1.16(0.70-1.92)$ & $1.40(0.76-2.57)$ \\
Religious service attendance (yes/no) & 239 & $2.89(1.82-4.60)$ & $2.86(1.85-4.41)$ \\
Frequency of religious service attendance & 239 & & $7.91(3.59-17.41)$ \\
$\quad$ Never & & $6.78(3.16-14.54)$ & $7.89(1.96-31.81)$ \\
Less than monthly & & $10.33(2.48-43.01)$ & $7.28(1.88-28.12)$ \\
$\quad$ Monthly & $4.07(1.48-11.17)$ & $1.96(0.76-5.04)$ \\
$\quad$ Weekly & - & $1.51(0.61-3.72)$ & - \\
$\quad$ More than weekly & & - & $0.10(0.03-0.37)$ \\
Psychosocial factors & & $0.17(0.06-0.44)$ & $0.42(0.20-0.85)$ \\
Self-esteem & 254 & $0.55(0.27-1.14)$ & $4.40(2.34-8.29)$ \\
Sense of personal power & 237 & $2.83(1.65-4.86)$ & \\
Peer-pressure & 248 & &
\end{tabular}

† Age adjusted logistic regressions, adjusted for effects of current age.

\# Odds ratios relative to attending religious service "More than weekly".

inequality) of 0.39 that places it between the the US (0.41) and the UK (0.36). Barbados also has one of the lowest rates of poverty in the Caribbean and Latin America, and has a high literacy rate according to the United Nations Development Program $[47,48]$. Despite these favorable indicators and a high degree of knowledge of condom use identified in successive KABP surveys, the present survey uncovered evidence of relationship imbalances with agedisparate partnering particularly at sexual debut.

The first sexual experience was associated with forcible sex or pressure to have sex in nearly $40 \%$ of respondents, a worrying finding that is consistent with a pattern of

Table 4 Unadjusted and age-adjusted associations for inter-generational sex (yes/no) in females who had ever had sex

\begin{tabular}{|c|c|c|c|}
\hline Factor & $\mathrm{N}$ & Unadjusted odds ratio $(95 \% \mathrm{Cl})$ & Age adjusted odds ratio $(95 \% \mathrm{Cl}) \dagger$ \\
\hline Age & 129 & $1.16(0.77-1.73)$ & $1.56(0.91-2.68)$ \\
\hline Age at first sex & 120 & $0.67(0.50-0.90)$ & $0.58(0.41-0.83)$ \\
\hline Condom use at first sex & 123 & $1.58(0.51-4.91)$ & $0.66(0.16-2.77)$ \\
\hline Willingness at first sex & 128 & $0.86(0.45-1.62)$ & $0.55(0.26-1.78)$ \\
\hline Enough money to cover necessities & 127 & $1.21(0.58-2.51)$ & $0.99(0.46-2.11)$ \\
\hline Enough money to cover luxuries & 124 & $0.72(0.35-1.51)$ & $0.60(0.23-1.56)$ \\
\hline Money or gifts from partner & 123 & $3.35(1.51-7.45)$ & $2.91(1.17-7.23)$ \\
\hline Religious service attendance (yes/no) & 119 & $1.48(0.50-4.37)$ & $0.88(0.27-2.87)$ \\
\hline Frequency of religious service attendance $\neq$ & 119 & & \\
\hline Never & & $1.13(0.22-5.90)$ & $0.54(0.08-3.54)$ \\
\hline Less than monthly & & $1.00(0.18-5.58)$ & $0.72(0.08-6.46)$ \\
\hline Monthly & & $0.60(0.07-5.43)$ & $0.64(0.07-6.22)$ \\
\hline Weekly & & $0.57(0.18-1.77)$ & $0.44(0.12-1.66)$ \\
\hline More than weekly & - & - & - \\
\hline \multicolumn{4}{|l|}{ Psychosocial factors } \\
\hline Self-esteem & 127 & $0.32(0.16-0.64)$ & $0.33(0.11-0.95)$ \\
\hline Sense of personal power & 122 & $0.77(0.33-1.83)$ & $1.10(0.47-2.56)$ \\
\hline Peer-pressure & 128 & $1.42(0.71-2.86)$ & $1.42(0.61-3.29)$ \\
\hline Morokoff subscale (pregnancy/STD risk) & 104 & $1.55(0.84-2.86)$ & $1.37(0.58-3.22)$ \\
\hline
\end{tabular}

† Age adjusted logistic regressions, adjusted for effects of current age. ‡ Odds ratios relative to attending religious service "More than weekly". 
sexual coercion, sexual abuse and high rates of interpersonal violence reported in the Caribbean literature $[5,19,26,49-53]$. Condom use was strikingly related to willingness to have sex, with a distribution of 2:1:0 in girls who were either willing:persuaded:forced to have sex at their first sexual encounter.

The strongest predictor of IG-sex was the age at first sex. The median age at first sex was 17 years. On the face of it this is later than reported by other studies in the region but apparent discrepancies may be explained by the way age at first sex was reported and by gender differences $[50,54,55]$. The authoritative multi-country Caribbean Youth Health Survey (CYHS) survey is often quoted out of context [50]. Commentators have reported the headline finding that nearly half of adolescents were 10 years or younger when they first had intercourse without stating the context that $65.9 \%$ of respondents in CYHS never had sexual intercourse. Furthermore, that headline figure included boys, in whom sexual initiation in the Caribbean has been consistently reported as occurring earlier than in girls [5,20,54-56]. Other regional studies have reported age at first sex as a mean, thereby failing to recognise the often skewed nature of 'time to event' data and possibly also failing to censor [37,57]. Our survey was in line with other Caribbean surveys reporting the same median age indicator $[5,20]$. The age of sexual initiation therefore remains a critical area for research influencing women's health in the region, since age at first sex is a modifiable risk factor linked not only to IG-sex, as reported here, but also a cluster of high risk health behaviors in Caribbean girls, including smoking, alcohol and drug use, truancy, and gang membership [58-62].

Regular participation in religious worship (at least weekly) was statistically significantly associated with a lower chance of reporting a sexual encounter with any-age partner. This is consistent with previous reports in the Caribbean [63-66]. The logistic regression analysis showing a statistically significant downward trend in peer pressure index with religious service attendance, and frequency of attendance, supported the notion of an external influence of religion. However, we could not confirm an association of religious worship with IG sex. Other social network information on schools, families, influential individuals, neighbourhoods and activity groups coupled with a more comprehensive network analysis will therefore be required to better understand the impact of belief systems on the likelihood of engaging in sex or inter-generational sex in adolescent females $[67,68]$.

Finally, it was noted that a cluster of psycho-social variables - self-esteem, sense of personal power, and peer pressure - were differentially associated with IG-sex $v s$. sex with any-age partner. The three variables were related to each other and to sex with any-age partner, yet the cluster fractured when applied to IG-sex, with low self-esteem solely associated with IG-sex. The survey also identified a strong association of multiple partnering with IG-sex. It should be noted, however, that the direction of the associations with multiple partners and self-esteem were not clear: was low self-esteem or multi-partnering a predictor of IG-sex? Or was exposure to IG-sex a cause of low self-esteem or multiple partnering?

We acknowledge limitations of this relatively small cross sectional study. The directionality of association cannot be inferred from this cross sectional survey. For example, low self-esteem might be a reason for early sexual experience or for involvement in IG sex. On the other hand, early sexual experience and involvement in IG sex might be a reason for having low self-esteem. Further qualitative research will be required to tease out causality and motivating factors and how these might differ between intergenerational relationships and those with any-age partner. We acknowledge that the dividing line can be blurred as to what constitutes transactional sex and what constitutes the normal exchange of gifts in a loving relationship. Hence, we caution against drawing the conclusion that the receipt of money or gifts was necessarily a risk factor for IG-sex, at least based on this survey. We acknowledge that the use of an interviewer may contribute a source of bias in our survey, although we sought to mitigate against this possibility by using experienced youth commissioners and training interviewers not to lead participants in their responses.

\section{Conclusion}

In conclusion, the most powerful predictor of IG-sex in this survey was age at first sex, with the risk being halved for each additional year that sexual initiation was delayed. Although not a widely reported indicator, a proportion of $13.2 \%$ of girls having IG-sex at sexual initiation was undoubtedly high. Together with evidence here and across the Caribbean of widespread sexual coercion at first sex, with concominantly diminished condom use, this brings into sharp focus what protective programmes can be devised, besides risk reduction strategies, to help Caribbean girls re-balance the power in relationships particularly during their first sexual encounter $[4,5,49]$. The promotion of self-esteem in young women has been highlighted as a positive prevention approach in recently formulated policy by the National HIV/AIDS Commission of Barbados designed to remove gender stereotypes and boost selfacclamation of young women within more equitable sexual relationships [69].

\section{Competing interests}

None of the authors disclose any competing interests from any organization, investments or patents that may in any way gain or lose financially from the publication of this manuscript. RCL discloses that he is president of the The Caribbean Cytometry \& Analytical Society, a registered Barbadian HIV charity 
(Barbados charitable organization \# 660), that funded this study and paid the article-processing fees of this manuscript. None of the authors declare any non-financial competing interests (political, personal, religious, ideological, academic, intellectual, commercial or any other) in relation to this manuscript.

\section{Authors' contributions}

ND made substantial contributions to the study design, acquisition and analysis of data, as well as intellectual content. CP contributed to conception, design, ethical approval, analysis of data and intellectual content. AK contributed to conception, design and interpretation of data, and intellectual content. KQ contributed to ethical approval, analysis, interpretation of data and critical revision of the manuscript. CC oversaw data collection, quality control and data management for the study. RP contributed to the conception, design and intellectual content of the study. IRH contributed to the design and led the statistical analysis of the study, as well as critical revision and intellectual content. RCL drafted the manuscript and contributed to the conception, design, and interpretation of the study, analysis of the data, and intellectual content of the manuscript. All authors read and approved the final manuscript.

\section{Acknowledgements}

The authors wish to acknowledge the assistance of Mrs. Lourdes SorianoRouco for data entry. The authors are particularly grateful for the professional work of the youth commissioners, Ministry of Youth, Family \& Sports, who administered this survey and without whom this work would not have been possible.

\begin{abstract}
Author details
${ }^{1}$ National HIV AIDS Commission, National AIDS Program, Bridgetown, Barbados. ${ }^{2}$ Department of Genito Urinary Medicine \& HIV, Southampton University, Southampton, UK. ${ }^{3}$ Department of Pediatrics, Faculty of Medical Sciences, University of the West Indies, Bridgetown, Barbados. ${ }^{4}$ Chronic Disease Research Centre, The University of the West Indies, Bridgetown, Barbados. ${ }^{5}$ Department of Youth Affairs, Ministry of Youth, Family \& Sports, Bridgetown, Barbados. ${ }^{6}$ Edmund Cohen Laboratory for Vascular Research, Chronic Disease Research Centre, University of the West Indies, Bridgetown BB11115, Barbados.
\end{abstract}

Received: 8 March 2013 Accepted: 21 November 2013 Published: 27 December 2013

\section{References}

1. UNAIDS World AIDS Day Report. 2011. http://www.unaids.org/en/media/ unaids/contentassets/documents/unaidspublication/2011/JC2216_ WorldAIDSday_report_2011_en.pdf. Accessed May 16 2012. 12-1-2011.

2. The Barbados HIVIAIDS Surveillance Report 2010. Barbados: HIV AIDS Programme, Ministry of Health; 2011.

3. Caribbean AIDS epidemic update 2008. 2012. http://data.unaids.org/pub/ Report/2008/jc1528_epibriefs_caribbean_en.pdf accessed 20/04/2012.

4. Bombereau G, Allen CF: Social and cultural factors driving the HIV epidemic in the Caribbean: a literature review. St. Augustine, Trinidad and Tobago: Caribbean Health Research Council; 2008. Accessed at: http://www. academia.edu/1811440/Social_and_cultural_factors_driving_the_HIV_ epidemic_in_the_Caribbean.

5. Ogunnaike-Cooke S, Kabore I, Bombereau G, Espeut D, O'Neil C, Hirnschall G: Behavioural Surveillance Surveys in Six Countries of the Organisation of Eastern Caribbean States (2005-2006). Port of Spain, Trinidad and Tobago: US Agency for International Development, Family Health International, Caribbean Epdemiology Centre and the Pan American Health Organisation; 2007.

6. Hope R: Addressing Cross-Generational Sex: A Desk Review of Research and Programs. Interagency Gender Working Group (IGWG) and the Interagency Youth Working Group (IYWG); 2007. Available at: http://www.iywg.org/sites/ iywg/files/CrossGenSex.pdf.

7. Luke N: Age and economic asymmetries in the sexual relationships of adolescent girls in sub-Saharan Africa. Stud Fam Plann 2003, 34:67-86.

8. UNAIDS Terminology Guidelines (October 2011). Accessed at: http://www. unaids.org/en/media/unaids/contentassets/documents/unaidspublication/ 2011/JC2118_terminology-guidelines_en.pdf. UNAIDS. 10-1-2011.
9. Luke N: Confronting the 'sugar daddy' stereotype: age and economic asymmetries and risky sexual behavior in urban Kenya. Int Fam Plan Perspect 2005, 31:6-14.

10. Chatterji M, Murray N, London D, Anglewicz P: The factors influencing transactional sex among young men and women in 12 sub-Saharan African countries. Soc Biol 2005, 52:56-72.

11. Bearinger $L H$, Sieving RE, Ferguson J, Sharma V: Global perspectives on the sexual and reproductive health of adolescents: patterns, prevention, and potential. Lancet 2007, 369:1220-1231.

12. Kelly RJ, Gray RH, Sewankambo NK, Serwadda D, Wabwire-Mangen F, Lutalo T, et al: Age differences in sexual partners and risk of HIV-1 infection in rural Uganda. J Acquir Immune Defic Syndr 2003, 32:446-451.

13. Gregson S, Nyamukapa CA, Garnett GP, Mason PR, Zhuwau T, Carael M, et al: Sexual mixing patterns and sex-differentials in teenage exposure to HIV infection in rural Zimbabwe. Lancet 2002, 359:1896-1903.

14. Kurz K, Luke N: Cross-generational and Transactional Sexual Relations in Sub Saharan Africa: Prevalence of Behavior and Implications for Negotiating Safer Sexual Practices. International Center for Research on Women/Population Services International; Sep 2002. Available at: http://www.icrw.org/files/ publications/Cross-generational-and-Transactional-Sexual-Relations-in-SubSaharan-Africa-Prevalence-of-Behavior-and-Implications-for-NegotiatingSafer-Sexual-Practices.pdf.

15. Dunkle $K L$, Jewkes $R$, Nduna $M$, Jama N, Levin J, Sikweyiya $Y$, et al: Transactional sex with casual and main partners among young South African men in the rural Eastern Cape: prevalence, predictors, and associations with gender-based violence. Soc Sci Med 2007, 65:1235-1248.

16. Maganja RK, Maman S, Groves A, Mbwambo JK: Skinning the goat and pulling the load: transactional sex among youth in Dar es Salaam, Tanzania. AIDS Care 2007, 19:974-981.

17. Luke N, Goldberg RE, Mberu BU, Zulu EM: Social Exchange and Sexual Behavior in Young Women's Premarital Relationships in Kenya. J Marriage Fam 2011, 73:1048-1064.

18. Allen CF, Edwards M, Williamson LM, Kitson-Piggott W, Wagner HU, Camara $B$, et al: Sexually transmitted infection service use and risk factors for HIV infection among female sex workers in Georgetown, Guyana. J Acquir Immune Defic Syndr 2006, 43:96-101.

19. Jones A: The Transactional Sexual Abuse of Children in the Caribbean. Accessed at: http://eprints.hud.ac.uk/9608/.

20. Organisation of Eastern Caribbean States and Health Economics Unit, Knowledge, Attitudes, Beliefs and Practices (KABP) Surveys on HIV/AIDS in Antigua and Barbuda, St. Kitts and Nevis, Dominica and Grenada: Synthesized Report. O.E.C.S.HIV/AIDS Programme Unit. St. Augustine, Trinidad and Tobago: Health Economics Unit, Centre for Health Economics, University of the West Indies; 2011.

21. USAID Caribbean: HIV/AIDS Health Profile. USAID; 2007. Accessed at: http:// www.old.msmgf.org/documents/Caribbean/NonGovernment/USAID CaribbeanPrfile.pdf.

22. Report on the Barbados National Youth KABP Survey on HIVIAIDS 2005-2006. Bridgetown, Barbados: Ministry of Education, Youth Affairs and Sports; 2007.

23. Report on National Knowledge, Attitudes, Behaviour \& Practices (KABP) Survey Year 2004: Report on National Knowledge, Attitudes, Behaviour \& Practices (KABP) Survey Year 2004, Ministry of Health. Kingston, Jamaica: Hope Enterprises Ltd; 2005. Accessed at: http://www.jamaica-nap.org/ nationalKABPreport_2004\%20Final.pdf.

24. Anderson H, Marcovici K, Taylor K: The UNGASS, Gender and Women's Vulnerability to HIV/AIDS in Latin America and the Caribbean. Pan-American Health Organization. 2002. Accessed at: http://www.paho.org/English/ad/ge/ GenderandHIV-revised0904.pdf.

25. Kempadoo K, Taitt A: Gender, Sexuality and Implications for HIV/AIDS in the Caribbean: A Review of Literature and Programmes. UNIFEM/IDRC: Prepared for; 2006.

26. LeFranc E, Samms-Vaughan M, Hambleton I, Fox K, Brown D: Interpersonal violence in three Caribbean countries: Barbados, Jamaica, and Trinidad and Tobago. Rev Panam Salud Publica 2008, 24:409-421.

27. Gage AJ, Hutchinson PL: Power, control, and intimate partner sexual violence in Haiti. Arch Sex Behav 2006, 35:11-24.

28. HIV/AIDS Survey Indicators Database: Measure DHS Online Tools. 2012. Accessed at: http://www.measuredhs.com/hivdata/.

29. Wood EB, Hutchinson MK, Kahwa E, Hewitt H, Waldron N: Jamaican adolescent girls with older male sexual partners. J Nurs Scholarsh 2011, 43:396-404.

30. Tureski K, O'Connor Anderson K, Rogers S, Cushnie A: Cross-Generational Relationships: Perceived Norms and Practices in Jamaica. Washington DC: 
C-Change/ FHI 360; 2012. Accessed at: http://www.pancap.org/attachments/ article/1015/Cross-Generational-Relationships-Jamaica.pdf.

31. Nigeria: Demographic and Health Survey 2003, ORC Macro. Abuja, Nigeria: National Population Commission; 2004. Accessed at: http://pdf.usaid.gov/ pdf_docs/Pnacx579.pdf.

32. Uganda Demographic and Health Survey 2006. Kampala, Uganda: Uganda Burea of Statistics; 2007. accessed at: http://www.ubos.org/onlinefiles/ uploads/ubos/pdf\%20documents/Uganda\%20DHS\%202006\%20Final\%20\% 20Report.pdf.

33. Tanzania Demographic and Health Survey 2004: ORC Macro. Dar es Salaam Tanzania: National Bureau of Statistics; 2005. Accessed at: http://www. measuredhs.com/pubs/pdf/FR173/FR173-TZ04-05.pdf.

34. Malawi Demographic and Health Survey 2004: ORC Macro. Zomba, Malawi National Statistical Office; 2004. Accessed at: http://www.measuredhs.com/ pubs/pdf/FR175/FR-175-MW04.pdf.

35. Ghana Demographic and Health Survey 2003: ORC Macro. Accra, Ghana: Ghana Statistical Service; 2004. Accessed at: http://www.measuredhs.com/ pubs/pdf/FR152/FR152.pdf.

36. Leclerc-Madlala S: Age-disparate and intergenerational sex in southern Africa: the dynamics of hypervulnerability. AIDS 2008, 22(Suppl 4):S17-S25.

37. Cremin I, Mushati P, Hallett T, Mupambireyi Z, Nyamukapa C, Garnett GP, et al Measuring trends in age at first sex and age at marriage in Manicaland, Zimbabwe. Sex Transm Infect 2009, 85(Suppl 1):i34-i40.

38. Wamoyi J, Fenwick A, Urassa M, Zaba B, Stones W: "Women's bodies are shops": beliefs about transactional sex and implications for understanding gender power and HIV prevention in Tanzania. Arch Sex Behav 2011, 40:5-15.

39. Nobelius AM, Kalina B, Pool R, Whitworth J, Chesters J, Power R: "You still need to give her a token of appreciation": the meaning of the exchange of money in the sexual relationships of out-of-school adolescents in rural southwest Uganda. J Sex Res 2010, 47:490-503.

40. Pulerwitz J, Gortmaker SL, De JW: Measuring Sexual Relationship Power in HIV/STD Research. Sex Roles 2000, 42(7/8):637-660.

41. Rosenberg M: Society and the Adolescent Child. Princeton, NJ: Princeton University Press; 1965.

42. Carter R: Social Policy Challenges in the Post Independence Era. Bridgetown, Barbados; 2006.

43. Gutierrez L, Hyun JH, Gillmore MR: Toward an understanding of (em) power(ment) for HIV/IDS prevention with adolescent women. Sex Roles 2000, 42:581-611.

44. Morokoff PJ, Quina K, Harlow LL, Whitmire L, Grimley DM, Gibson PR, et al: Sexual Assertiveness Scale (SAS) for women: development and validation. J Pers Soc Psychol 1997, 73:790-804

45. Weiser SD, Leiter K, Bangsberg DR, Butler LM, Percy-de KF, Hlanze Z, et al: Food insufficiency is associated with high-risk sexual behavior among women in Botswana and Swaziland. PLoS Med 2007, 4:1589-1597.

46. Lopman B, Lewis J, Nyamukapa C, Mushati P, Chandiwana S, Gregson S: HIV incidence and poverty in Manicaland, Zimbabwe: is HIV becoming a disease of the poor? AIDS 2007, 21(Suppl 7):S57-S66.

47. The World Bank, by Country. Barbados. Accessed at: http://data.worldbank.org/ country/barbados. 5-17-2012.

48. United Nations Human Development Index: United Nations Development Program. 5-17-2012. 2012. Accessed at: http://hdrstats.undp.org/en/ countries/profiles/BRB.html.

49. Bombereau G: Systematic review related to HIV risk behaviours in the Caribbean among children, young adults and vulnerable populations. Port of Spain, Trinidad and Tobago: Caribbean Epidemiology Centre; 2007.

50. Halcon L, Blum RW, Beuhring T, Pate E, Campbell-Forrester S, Venema A: Adolescent health in the Caribbean: a regional portrait. Am J Public Health 2003, 93:1851-1857.

51. Gomez AM, Speizer IS, Beauvais H: Sexual violence and reproductive health among youth in Port-au-Prince, Haiti. J Adolesc Health 2009, 44:508-510.

52. Bailey W, Le Franc E, Blanche C: Partnering and violence. Caribbean Dialogue: A policy bulletin of Caribbean affairs 1998, 4(2):11-18.

53. Jones A, Trotman-Jemmott E: Perceptions of, attitudes to and opinions on child sexual abuse in the Eastern Caribbean. 2009. http://www.unicef.org/infobycountry/ files/Child_Sexual_Abuse_in_the_Eastern_Caribbean_Final_9_Nov.pdf.

54. Kurtz SP, Douglas KG, Lugo Y: Sexual risks and concerns about AIDS among adolescents in Anguilla. AIDS Care 2005, 17(Suppl 1):S36-S44.
55. Stallworth J, Roofe M, Clark LF, Ehiri JE, Mukherjee S, Person S, et al: Predictors of sexual involvement among adolescents in rural Jamaica. Int J Adolesc Med Health 2004, 16:165-178

56. Smikle MF, Dowe G, Hylton-Kong T, Williams E, Baum M: Risky behaviour in Jamaican adolescent patients attending a sexually transmitted disease clinic. West Indian Med J 2000, 49:327-330.

57. Zaba B, Pisani E, Slaymaker E, Boerma JT: Age at first sex: understanding recent trends in African demographic surveys. Sex Transm Infect 2004, 80(Suppl 2):ii28-ii35.

58. Ohene SA, Ireland M, Blum RW: The clustering of risk behaviors among Caribbean youth. Matern Child Health J 2005, 9:91-100.

59. Baumgartner JN, Waszak GC, Tucker $H$, Wedderburn M: The influence of early sexual debut and sexual violence on adolescent pregnancy: a matched case-control study in Jamaica. Int Perspect Sex Reprod Health 2009, 35:21-28.

60. Zaba B, Isingo R, Wringe A, Marston M, Slaymaker E, Urassa M: Influence of timing of sexual debut and first marriage on sexual behaviour in later life: findings from four survey rounds in the Kisesa cohort in northern Tanzania. Sex Transm Infect 2009, 85(Suppl 1):i20-i26.

61. Hallett TB, Lewis JJ, Lopman BA, Nyamukapa CA, Mushati P, Wambe M, et al: Age at first sex and HIV infection in rural Zimbabwe. Stud Fam Plann 2007, 38:1-10

62. Glynn JR, Kayuni N, Floyd S, Banda E, Francis-Chizororo M, Tanton C, et al: Age at menarche, schooling, and sexual debut in northern Malawi. PLoS One 2010, 5:e15334

63. Ohene SA, Ireland M, Blum RW: Sexually-inexperienced Caribbean youth: Correlates of delayed sexual debut. Adolesc Fam Health 2003, 3:177-184.

64. Bombereau G: HIV/AIDS prevention in the Caribbean: between religious cultures and sexual behaviours. Canada: University of Chicoutimi; 2005.

65. Blum RW, Halcon L, Beuhring T, Pate E, Campell-Forrester S, Venema A: Adolescent health in the Caribbean: risk and protective factors. Am J Public Health 2003, 93:456-460.

66. McBride DC, Freier MC, Hopkins GL, Babikian T, Richardson L, Helm H, et al: Quality of parent-child relationship and adolescent HIV risk behaviour in St. Maarten. AIDS Care 2005, 17 Suppl 1:S45-S54.

67. Nduna M, Jewkes RK, Dunkle KL, Shai NP, Colman I: Associations between depressive symptoms, sexual behaviour and relationship characteristics: a prospective cohort study of young women and men in the Eastern Cape. South Africa. J Int AIDS Soc 2010, 13:44.

68. Blum RW, Ireland M: Reducing risk, increasing protective factors: findings from the Caribbean Youth Health Survey. J Adolesc Health 2004, 35:493-500.

69. Research Sub-Committee NHAC: Towards a sexual health policy balancing positive prevention strategies with risk reduction. Barbados: National HIV/AIDS Commission; 2012

doi:10.1186/1472-6874-13-53

Cite this article as: Drakes et al:: Prevalence and risk factors for intergenerational Sex: a cross-sectional cluster survey of Barbadian females aged 15-19. BMC Women's Health 2013 13:53.

\section{Submit your next manuscript to BioMed Central and take full advantage of:}

- Convenient online submission

- Thorough peer review

- No space constraints or color figure charges

- Immediate publication on acceptance

- Inclusion in PubMed, CAS, Scopus and Google Scholar

- Research which is freely available for redistribution 